\title{
Complexity revealed in the greening of the Arctic
}

Reference

Myers-Smith, I.H., Kerby, J.T., Phoenix, G.K. et al. Complexity revealed in the greening of the

Arctic. Nat. Clim. Chang. 10, 106-117 (2020). https://doi.org/10.1038/s41558-019-0688-1

Weblink

https://www.nature.com/articles/s41558-019-0688-1

9

Isla H. Myers-Smith ${ }^{1 *}$, Jeffrey T. Kerby ${ }^{2,3 *}$, Gareth K. Phoenix ${ }^{4}$, Jarle W. Bjerke ${ }^{5}$, Howard E. Epstein $^{6}$, Jakob J. Assmann ${ }^{1,7}$, Christian John ${ }^{3}$, Laia Andreu-Hayles ${ }^{8}$, Sandra Angers-Blondin ${ }^{1}$, Pieter S.A. Beck ${ }^{9}$, Logan T. Berner ${ }^{10}$, Uma S. Bhatt ${ }^{11}$, Anne D. Bjorkman ${ }^{12,13}$, Daan Blok ${ }^{14}$, Anders Bryn $^{15}$, Casper T. Christiansen ${ }^{16}$, J. Hans C. Cornelissen ${ }^{17}$, Andrew M. Cunliffe ${ }^{18}$, Sarah C. Elmendorf ${ }^{19}$, Bruce C. Forbes ${ }^{20}$, Scott J. Goetz ${ }^{10}$, Robert D. Hollister ${ }^{21}$, Rogier de Jong ${ }^{22}$, Michael M. Loranty $^{23}$, Marc Macias-Fauria ${ }^{24}$, Kadmiel Maseyk ${ }^{25}$, Signe Normand ${ }^{7}$, Johan Olofsson ${ }^{26}$, Thomas C. Parker $^{27}$, Frans-Jan W. Parmentier ${ }^{28,29,30}$, Eric Post ${ }^{3}$, Gabriela Schaepman-Strub ${ }^{31}$, Frode Stordal ${ }^{28}$, Patrick F. Sullivan ${ }^{32}$, Haydn J. D. Thomas ${ }^{1}$, Hans Tømmervik ${ }^{5}$, Rachael Treharne ${ }^{4}$, Craig E. Tweedie $^{33}$, Donald A. Walker ${ }^{34}$, Martin Wilmking ${ }^{35}$, Sonja Wipf ${ }^{36}$

* Joint first authors

1. School of GeoSciences, University of Edinburgh, Edinburgh, EH9 3FF, UK

2. Neukom Institute for Computational Science and the Institute for Arctic Studies, Dartmouth College, 78 College Street, Hanover, $\mathrm{NH}, 03755$, USA

3. Department of Wildlife, Fish, and Conservation Biology, University of California, Davis, One 25 Shields Ave., Davis, CA, 95616, USA

6 4. Department of Animal and Plant Sciences, University of Sheffield, Western Bank, Sheffield, S10 $7 \quad 2 \mathrm{TN}, \mathrm{UK}$

5. Norwegian Institute for Nature Research, FRAM - High North Research Centre for Climate and the Environment, P.O. Box 6606 Langnes, NO-9296 Tromsø, Norway 
6. Department of Environmental Sciences, University of Virginia, Charlottesville, VA, 22904-4123, USA

7. Section for Ecoinformatics and Biodiversity and Arctic Research Center, Department of Bioscience, University of Aarhus, Ny Munkegade 114, Building 1540, DK-8000 Aarhus C, Denmark

8. Lamont-Doherty Earth Observatory of Columbia University, 61 Route 9W, Palisades, NY, 10964, USA

9. European Commission, Joint Research Centre, 21027 Ispra VA, Italy

10. School of Informatics, Computing and Cyber Systems, Northern Arizona University, AZ, 86011, USA

11. Department of Atmospheric Sciences, University of Alaska Fairbanks, 2156 Koyukuk Drive, Fairbanks, AK, 99775-7320, USA

12. Senckenberg Gesellschaft für Naturforschung, Biodiversity and Climate Research Centre, Senckenberganlage 25, D-60325 Frankfurt am Main, Germany

13. Department of Biological and Environmenal Sciences, University of Gothenburg, PO Box 461, Gothenburg SE-405 30, Sweden

14. Netherlands Organisation for Scientific Research, Laan van Nieuw Oost-Indië 300, NL-2593

CE The Hague, The Netherlands

15. Natural History Museum, University of Oslo, PB 1172 Blindern, 0318 Oslo, Norway

16. NORCE Norwegian Research Centre \& Bjerknes Centre for Climate Research, Jahnebakken

5, 5007 Bergen, Norway

17. Systems Ecology, Department of Ecological Science, Faculty of Science, Vrije Universiteit, De Boelelaan 1085, 1081 HV Amsterdam, The Netherlands

18. School of Geography, University of Exeter, Exeter, EX4 4RJ, UK

19. Institute for Arctic and Alpine Research, University of Colorado, Boulder, CO, 80303, USA

20. Arctic Centre, University of Lapland, Box 122, FIN-96101 Rovaniemi, Finland

21. Biology Department, Grand Valley State University, 1 Campus Drive, Allendale, MI, 49401, USA

22. Department of Geography, University of Zürich, Winterthurerstrasse 190, 8057 Zurich, Switzerland 
59

60

61

62

63

64

65

66

67

68

69

70

71

72

73

74

75

76

77

78

79

80

81

82

83

84

23. Department of Geography, Colgate University, 13 Oak Dr, Hamilton, NY, 13346, USA

24. School of Geography \& the Environment, University of Oxford, S Parks Rd, Oxford, OX1 3QY, UK

25. School of Environment, Earth and Ecosystem Sciences, The Open University, Milton Keynes, MK7 6AA, UK

26. Umeå University, Department of Ecology and Environmental Sciences, KB.H4, Linnaeus

Väg 6, 90187 Umeå, Sweden

27. Biological and Environmental Sciences, School of Natural Sciences, University of Stirling,

Stirling, FK9 4LA, UK

28. Department of Geosciences, University of Oslo, Postboks 1022 Blindern, 0315 Oslo, Norway

29. Department of Physical Geography and Ecosystem Science, Lund University, Sölvegatan 12, 22362 Lund, Sweden

30. Department of Arctic and Marine Biology, UiT-The Arctic University of Norway, N-9037,

Tromsø, Norway

31. Department of Evolutionary Biology and Environmental Studies, University of Zurich, Winterthurerstr. 190, 8057 Zurich, Switzerland

32. Environment and Natural Resources Institute, University of Alaska Anchorage, 3211

Providence Dr., Anchorage, AK, 99508, USA

33. Department of Biological Sciences and the Environmental Science and Engineering Program, University of Texas at El Paso, 500 W University Ave, El Paso, TX 79968, USA

34. Institute of Arctic Biology, University of Alaska Fairbanks, 2140 Koyukuk Drive, Fairbanks, AK, 99775, USA

35. Institute of Botany and Landscape Ecology, University Greifswald, Soldmannstrasse 15, D17487 Greifswald, Germany

36. WSL Institute for Snow and Avalanche Research SLF, Team Mountain Ecosystems, Fluelastrasse 11, 7260 Davos Dorf, Switzerland 


\section{Editor's Summary}

As tundra ecosystems respond to rapid Arctic warming, satellites records suggest a widespread greening. This Perspective highlights the challenges of interpreting complex Arctic greening trends and provides direction for future research by combining ecological and remote sensing approaches.

\section{Abstract}

As the Arctic warms, vegetation is responding and satellite measures indicate widespread greening at high latitudes. This 'greening of the Arctic' is among the world's most significant large-scale ecological responses to global climate change. However, a consensus is emerging that the underlying causes and future dynamics of so-called Arctic greening and browning trends are more complex, variable, and inherently scale dependent than previously thought. Here, we summarize the complexities of observing and interpreting high-latitude greening to identify key priorities for future research. Incorporating satellite and proximal remote sensing with in-situ data, while accounting for uncertainties and scale issues will advance the study of past, present, and future Arctic vegetation change.

\section{Main text}

The Arctic has warmed at more than twice the rate of the rest of the planet in recent decades ${ }^{1,2}$. Over the past forty years, satellite-derived vegetation indices have indicated widespread change at high latitudes $^{3-16}$. Satellite records allow for the quantification of change in places that are otherwise unevenly sampled by in-situ ecological observations ${ }^{17}$. Positive trends in satellite-derived vegetation indices (often termed Arctic greening) ${ }^{15}$ are generally interpreted as signs of in-situ increases in vegetation height, biomass, cover and abundance ${ }^{5,18,19}$ associated with warming ${ }^{5,14}$. In the most recent Intergovernmental Panel on Climate Change report, tundra vegetation change including greening trends derived from satellite records ${ }^{20}$ was identified as one of the clearest examples of the terrestrial impacts of climate change. Large-scale vegetation-climate feedbacks at high latitudes associated with greening could alter global soil carbon storage and the surface energy budget ${ }^{21,22}$. In recent years, slowing or reversal of apparent greening from satellite studies have been reported in some regions (sometimes termed Arctic browning) $3,4,12,13,15,23,24$. This slowdown is seemingly at 
114

odds with earlier responses to long-term warming trends ${ }^{3,25}$. Research now indicates substantial heterogeneity in vegetation responses to climate change in the $\operatorname{Arctic}^{18,19,26,27}$. However, the mechanistic links between satellite records and in-situ observations ${ }^{3,6,24}$ remain unclear due to conceptual and technical barriers in their analysis and combined interpretation.

\section{A review of Arctic greening}

The terms Arctic 'greening' and 'browning' can have different meanings in the remote sensing and ecology literatures. From a remote sensing perspective, 'greening' (hereafter spectral greening) generally refers to a positive trend $\mathrm{d}^{4,5,7,8,10,13-15}$, and 'browning' (hereafter spectral browning) generally refers to negative trend in satellite-derived vegetation indices ${ }^{3,4,12,13,15,23,24}$. Less frequently, greening is also used to describe advances in the seasonal timing of these vegetation proxies ${ }^{4,28}$. From a fieldecology perspective, greening (hereafter vegetation greening) and browning (hereafter vegetation browning) refer to field-observed changes in vegetation ${ }^{4,12,13,24}$. Historically, the general terms greening and browning were thus used to describe both a proxy of vegetation change and/or vegetation change itself depending on context. This lack of precise usage causes conceptual misunderstandings about Arctic greening and attribution to the drivers of change. Here, we present the current understanding of Arctic spectral and vegetation greening and browning to lay the foundations for a consensus between the remote sensing and field ecology perspectives.

\section{Vegetation indices as proxies of vegetation productivity}

Long-term trends in global vegetation dynamics are most commonly quantified from time series of spectral vegetation indices derived from optical satellite imagery (Figure 1). These indices are designed to isolate signals of leaf area and green vegetation cover from background variation by emphasizing reflectance signatures in discrete regions of the radiometric spectrum ${ }^{6,29-32}$. Common vegetation indices include the Normalized Difference Vegetation Index (NDVI, Figure 2), Enhanced Vegetation Index (EVI) and Soil Adjusted Vegetation Index (SAVI), among others ${ }^{33-35}$. NDVI correlates with biophysical vegetation properties like Leaf Area Index ( $\mathrm{LAl}$ ) and the fraction of Absorbed Photosynthetically Active Radiation (fAPAR) ${ }^{14,36-39}$. However, these vegetation indices were not developed in polar contexts ${ }^{40}$ and are only proxies of photosynthetic activity rather than 
143 direct measurements of biological productivity ${ }^{33,39,41}$. NDVI is the most commonly used vegetation 144 index because it is simple to calculate with spectral bands monitored since the launch of early145 generation Earth-observing satellites in the 1970s (Figure 2) and is perhaps best defined as a 146 measure of above-ground vegetation greenness.

148 The longest-term openly-available NDVI datasets have been produced from satellite-based sensors 149 with broad spatial coverages and different sampling frequencies. The most common datasets 150 include: 1) the Advanced Very-High-Resolution Radiometer (AVHRR - 1982 to present) on board 151 NOAA satellites, 2) the Moderate-resolution Imaging Spectroradiometer (MODIS - 2000 to present) 152 on board NASA satellites, and 3) NASA-USGS Landsat sensors (1972 to present). Most studies of 153 long-term trends calculate annual measures of maximum NDVI to derive change over space and 154 time, though time-integrated approaches are also used ${ }^{30,42-44}$. However, trends in NDVI data 155 produced from different satellite datasets or using different methods do not always correspond at a 156 given location ${ }^{6,45,46}$ (Figure 1a,c). Thus, it can be challenging to distinguish ecological change from 157 differences due to methods and sensor/platform-related issues when interpreting localised spectral 158 greening or browning signals (Table 1, Figure 2). 
160

161

162

163

164

165

166

\section{Ecological factors influencing greening and browning trends}

The ecological processes underlying spectral greening or browning measured by satellites are diverse and may unfold across overlapping scales, extents and timeframes. In tundra ecosystems, vegetation changes linked to spectral greening could include: encroachment of vegetation on previously non-vegetated land surfaces ${ }^{18,47}$, changes in community composition - such as tundra shrub expansion ${ }^{5,19,27}$, and/or changes in plant traits such as height ${ }^{48,49}$, leaf area, or phenology ${ }^{50-52}$. Tall shrub tundra typically has a higher NDVI than other tundra plant types ${ }^{49,53,54}$, and bare ground ${ }^{29}$ has a much lower NDVI than vegetated tundra (Figure 2). Spectral browning could be related to a variety of factors including for example loss of photosynthetic foliage ${ }^{12}$ or increases in bare ground cover due to permafrost thaw ${ }^{55}$ (Figure 1). Thus, changes in the species composition, growth form and traits of plant communities can influence greening and browning trends.

\section{Physical factors influencing greening and browning trends}

Widespread non-biological changes in high-latitude ecosystems could confound and decouple spectral greening or browning trends from changes in plant productivity (Table 1). Land cover, topography, and associated soil moisture, surface water, land-surface disturbances and snow-melt dynamics can all influence the measured spectral greenness of landscapes ${ }^{56-63}$ and likely influence greening trends. For example, changes in the extent of summer snow patches ${ }^{63}$, surface water ${ }^{60}$ or surface soil moisture ${ }^{59}$ that are often associated with landscape-scale topographic variation could influence the measured NDVI of the land surface. At high latitudes, optical satellite sensors are only effective for a short annual window due to the prolonged polar night, while low sun angles and persistent cloud cover reduce data quality in the summer season (Table 1). The unique physical properties of high-latitude ecosystems in addition to the constraints of polar remote sensing are often underemphasized in remote sensing studies of Arctic vegetation change. 


\section{Arctic browning and heterogeneity of spectral greening trends}

Not all areas of the Arctic are spectrally greening (Figure 1), and in recent years spectral browning and heterogeneity of spectral greening trends have been highlighted ${ }^{3,4,12,13,23}$. Ecological explanations for vegetation browning include for example the sudden loss of photosynthetically active foliage due to extreme climatic events ${ }^{64-67}$, biological interactions (e.g., disease or herbivore outbreaks) $^{68-70}$, permafrost degradation ${ }^{23,55}$ (Figure 1), increases in standing dead biomass ${ }^{71}$, coastal erosion $^{72}$, salt inundation ${ }^{73}$, altered surface water hydrology ${ }^{74,75}$ or fire $e^{9,76,77}$. Spectral browning, however, could be attributed to reduced productivity caused by adverse changes in growing conditions such as lower water availability, shorter growing seasons ${ }^{3}$ or nutrient limitation ${ }^{27}$. Nonetheless, long-term spectral greening trends remain far more pervasive than spectral browning in tundra ecosystems. Figures vary from 42\% greening and $2.5 \%$ browning from 1982 to 2014 in the GIMMS3g AVHRR dataset ${ }^{78}, 20 \%$ greening and 4\% browning from 2000 to 2016 in Landsat data $^{15}$ and estimates of $13 \%$ greening and $1 \%$ browning for the MODIS trends calculated for 1000 random points in the tundra polygon in Figure 1 from 2000 to 2018. At circumarctic scales, the magnitude, spatial variability, and proximal drivers of patterns and trends of spectral greening versus browning are not well understood.

\section{Correspondence between satellite and ground-based observations}

Evidence for correspondence among in-situ vegetation change and trends in satellite-derived vegetation indices is mixed ${ }^{47,79-81}$. NDVI trends across satellite datasets do not necessarily directly correspond with one another ${ }^{6,9}$, nor does any one sensor or vegetation index combination correspond directly with in-situ vegetation change ${ }^{47}$. For example, NDVI has been related to interannual variation in radial shrub growth ${ }^{5,10,82}$, yet how radial growth links to change in leaf area, aboveground biomass, or landscape measures of productivity is not always clear ${ }^{83-85}$ (Figure 3). AVHRR NDVI greening trends did not correspond with the lack of change observed with Landsat NDVI data and in-situ plant composition between 1984 and 2009 in North Eastern Alaska ${ }^{47}$. Direct comparisons of productivity changes from vegetation cover estimates ${ }^{18,86}$, biomass harvests ${ }^{53}$ or shrub growth ${ }^{87}$ are complicated by the lack of annual-resolution in-situ data and low sampling replication across the landscape. We attribute the mixed evidence for correspondence between in- 
situ and satellite-derived measures of tundra vegetation change and greening to the complexities of existing terminology, challenges of interpretation of spectral vegetation indices at high latitudes, and the scaling issues as outlined below.

In addition to productivity analyses, changes in growing season length and advances in plant phenology have been documented using both satellite ${ }^{43,78,88-91}$ and ground-based datasets, and here also paired comparisons do not always correspond (Figure 4). Measures of longer growing seasons have been attributed to earlier snowmelt and/or earlier leaf emergence in spring ${ }^{92}$, and longer periods of photosynthetic activity or later snowfall in autumn ${ }^{93}$. However, few studies have monitored both leaf emergence and senescence of tundra plants in situ and so far provide no evidence for an increasing growing period at specific sites ${ }^{94,95}$. In addition, community-level analyses indicate shorter flowering season lengths around the tundra biome ${ }^{50}$. Shifts in plant phenology with warming ${ }^{50}$ could also be linked to changing species composition or diversity ${ }^{18,48,86}$, thus influencing the phenological diversity across the landscape ${ }^{96,97}$. Satellite records may not capture the ecological dynamics of vegetation phenology at high latitudes, as snow cover can obscure the plant seasonal signal and deciduous plants only make up a portion of the vegetated land cover. Thus, uncertainty remains whether satellite-derived changes in circumarctic phenology represent a longer snow-free period uncoupled from the vegetation response or an actual realized longer growing season of plants ${ }^{94,98-}$ 100.

\section{Clarifying the terminology}

To distinguish spectral greening and browning events from longer-term trends, we propose clarified definitions of events and trends. For an individual pixel, we define the spectral trend as an increase or decrease in NDVI (or other spectral vegetation index) over decadal time scales and a spectral event as a temporal outlier in the vegetation index relative to the long-term trend. Trends should be determined using a Theil-Sen estimator or similar robust statistical test for analyses of satellite data $^{30,101}$. We define a spectral greening trend as an increase of the vegetation index over decadal time scales. In situ, we interpret a vegetation greening trend as improved conditions for photosynthesis, reduced resource limitation and/or positive responses to disturbance in plant 
243

communities, resulting in greater aboveground biomass, leaf area, productivity or changes in plant community composition. We define a spectral browning trend as a decrease in the vegetation index over decadal time scales. A vegetation browning trend may correspond with an in-situ change in vegetation productivity due to plant dieback or loss of vegetation cover through biotic or abiotic disturbances. We define spectral greening events as short-term increases in vegetation index greenness that can be attributed to an ecological process such as revegetation of ground cover after fire and spectral browning events as short-term decreases in the vegetation index that can be attributed to a disturbance such as permafrost thaw or plant dieback. The definitions we propose here distinguish between slower acting climatic or biotic drivers of greening or browning trends versus event-driven changes caused by weather, biotic pulses, or other regional events such as fire.

\section{Differentiating events and trends}

In any measure of remotely sensed or field-based greening separate consideration of trends and events will increase ecological interpretability (Figure 5). Spectral greening and browning trends operate at any spatial scale, from localised patches to landscapes or even biome extents over decades. In contrast, spectral greening and browning events, such as those caused by vegetation dieback or rapid vegetation increase after disturbance, are often restricted to patch and regional scales over shorter durations. Events often have more limited extents relative to trends due to their proximal causes, like changes in herbivory or precipitation. Broader scale events are also possible (e.g. globally synchronized reductions in vegetation productivity caused by changes in insolation related to an intense volcanic eruption ${ }^{102}$ ). Therefore, greening or browning events might be embedded within overall spectral greening or browning trends, both temporally and/or spatially, without necessarily driving them (Figure 5). Examining the trend direction, magnitude and variance around the fit over time can shape more detailed investigations into the ecological interpretation of Arctic spectral greening trends.

\section{The influence of baselines and temporal sampling}

The baseline to which we compare productivity change will influence our interpretation of trends ${ }^{103}$. Spectral greening or browning trends and events may result in threshold changes where on-the- 
272 ground productivity does not return to the longer-term baseline (Figure 5; e.g., pulse in recruitment

273 at treeline $e^{104}$ or shrubline ${ }^{105}$ or a large fire ${ }^{77}$ ). In both satellite datasets and field observations, the 274 baseline conditions are often constrained by the limitations of data availability rather than any 275 deliberately selected starting point ${ }^{6}$. The low temporal sampling frequency of a few days to a few 276 weeks of many legacy remote-sensing datasets (e.g., AVHRR, MODIS, Landsat, etc.) also 277 introduces temporal scale-dependent effects that may be magnified in Arctic systems (Table 1). For 278 example, comparisons of phenology across latitudes can be less reliable at higher versus lower 279 latitudes due to shorter growing seasons and therefore fewer satellite data collection points for use 280 in change detection analyses ${ }^{42,88,89}$. Metrics based on the annual maximum NDVI of a given pixel 281 are more likely to be influenced by temporal sampling artefacts at high latitudes than those that 282 integrate productivity estimates through time, such as the growing season integrated NDVI 283 (GSINDVI $)^{42}$, time-integrated NDVI (TiNDVI) ${ }^{43}$ or early growing season integrated NDVI indices ${ }^{44}$. 284 Trends in either instance could be observed or not observed due to statistical reasons related to 285 sample size and/or the strength or linearity of the trend. Thus, simple linear analyses of annual 286 greenness metrics derived from satellite data may not always capture real-world ecological change 287 (Figure 5). 


\section{Challenges in the interpretation of vegetation indices}

In addition to the need for more clearly defined terms, challenges remain in the ecologically meaningful interpretation of long-term trends in optical satellite data, especially at high latitudes. The statistical relationship between a vegetation index and biomass, leaf area, phenology, or any other measures of productivity can vary due to a suite of intrinsic (e.g., sensor design, quality flagging algorithms), extrinsic (e.g., atmospheric conditions, sun angle, snow cover) ${ }^{6,106}$ and biological factors ${ }^{107}$ (Table 1). For example, the centre wavelength and width of spectral bands (e.g., in the red or near-infrared) used to generate vegetation indices were designed for different purposes in different sensors (Figure 2). While the NDVI formula may be the same, the covered spectral wavelength ranges differ between different datasets ${ }^{108}$ (Figure $2 \mathrm{~b}$ ). Thus, the datasets may be more or less sensitive to specific non-vegetative influences, such as atmospheric scattering or the magnitude of spectral mixing associated with non-vegetated surfaces ${ }^{57}$. Spectral unmixing is the process of decomposing the spectral signature of a mixed pixel into the abundances of a set of endmember categories ${ }^{109}$. Longer-term vegetation change is difficult to resolve from cross-sensor comparisons among different satellite datasets or even among intercalibrations of the same sensor type (Figure 1). For these reasons, caution is warranted when comparing vegetation indices derived from different satellite products or even versions of the same product with different atmospheric corrections, quality assessments, and spatial/temporal compositing approaches ${ }^{6,108}$. Differences in NDVI signal processing are actively studied by the remote-sensing community (Table 1), but could be better accounted for or quantified in Arctic greening studies.

\section{Nonlinearities in NDVI as a vegetation proxy}

Direct interpretations of vegetation changes from spectral data are contingent on the local relationship between NDVI and in-situ vegetation. The statistical relationships between vegetation indices and measures of Arctic vegetation biomass are nonlinear ${ }^{29,110}$ (Figure 2). This nonlinearity presents challenges for trend interpretation that are illustrated in Figure 2a. Here, an absolute increase in biomass for a 'low biomass' community towards a 'moderate biomass' community would result in a positive NDVI trend, but that same absolute biomass increase from moderate to high biomass would show virtually no trend in NDVI due to saturation (Figure 2). Thus, the relationship to 
common ecological variables like changes in biomass or shrub ring widths (Figure 4) can be obscured by nonlinearities. Because the greening and browning terms are tied to changes in vegetation proxies, rather than direct biological measures, a lack of correspondence could occur between remotely-sensed vegetation proxies and in-situ vegetation change (Figure 2, 4 and 5). Such potential discrepancies exemplify why caution should be used when interpreting linear trends in proxies like NDVI (Figure 1) that are nonlinearly related to vegetation productivity without the use of in-situ data to corroborate conclusions.

\section{Scaling issues in Arctic greening analyses}

Scale and hierarchies present a longstanding challenge in the interpretation of remotely-sensed vegetation proxies ${ }^{111-113}$ (Figure 5). All long-term vegetation proxy time series (Landsat, MODIS, AVHRR) spatially aggregate spectral data to pixels (i.e., grains) that span hundreds of square metres to tens of square kilometres. The spectral signatures of plants and non-vegetative features in a landscape are reduced to a single value. The loss of variability within pixels masks information useful for the attribution of greening signals to processes across ecological hierarchies from populations and communities to ecosystems (Table 1, Figure 3 and 5). For example, within a single AVHRR GIMMS3g pixel, a subselection of $1 \times 1 \mathrm{~km}$ pixels are upscaled to $8 \times 8 \mathrm{~km}^{32}$. Within this aggregated pixel, ecological contributions to spectral greening signals such as increased shrub cover on southfacing slopes or revegetation of drained lake beds may be mixed with browning signals from for example disturbances such as retrogressive thaw slumps or vegetation trampling by herbivores (Figure 1). High-latitude pixels may also contain shadows caused by low-sun angle, patchy snowand/or cloud-cover (Table 1). Thus, the emergent time series from such a pixel describes no single vegetation dynamic or environmental factor, but rather their integrated spectral responses. Broadscale patterns of spatial variability in greening and browning across pixels are also influenced by grain size ${ }^{113}$ (Figure 1, 2, 5). Finer resolution satellites such as Landsat can reduce, but not necessarily eliminate such spectral mixing ${ }^{15}$. However, the extent to which the sometimescontradictory greening and browning signals found across different spectral datasets can be attributed to the influence of the scale of measurement is poorly understood. 


\section{Complexities of capturing phenology}

Measuring landscape phenology with satellite data presents additional challenges to ecological interpretation of Arctic greening (Table 1). The variability of timing of satellite imagery from year to year particularly at high latitudes ${ }^{91}$ can confound measures of phenology (known as phenometrics). Cloud or fog cover is highly variable and sensitive to changing sea ice conditions in coastal Arctic sites $^{44}$. Seasonal variation in cloud and fog cover influences both data availability and image compositing approaches in many phenology products $^{91}$. In addition, vegetation metrics from early spring are much more likely to be influenced by snow, standing water or low sun angle than those closer to peak biomass in mid- to late-summer ${ }^{8,54,59}$. However, early spring is a critical period for establishing a baseline for curve fitting or thresholding used to derive phenometrics. Ultimately no phenometric is best suited to all Arctic environments or time periods ${ }^{114}$. Snow regimes and land cover variability differ annually and regionally and thus phenometrics using coarse-grain imagery integrate different abiotic and biotic signals at different points in space and time ${ }^{114}$. Phenological differences of days to weeks or even months can result from analyses using different methods and metrics for the same datasets at the same location ${ }^{115}$. These relative differences are of substantial ecological importance given the short growing seasons of the $\operatorname{Arctic}^{78,114}$ (Figure 4). Circumarctic analyses of vegetation indices generally indicate that phenological shifts in the spectral greenness of the land surface are widespread ${ }^{78,88-90}$. However, the magnitude and extent of spatial and temporal scaling issues in high-latitude remotely-sensed phenology trends warrant further consideration and research $^{112}$.

\section{Towards a consensus perspective on Arctic greening}

The fields of remote sensing and field-based ecology will benefit from jointly addressing the complexities of interpreting spectral and vegetation greening and browning trends. Analyses from one satellite platform or one specific ecological context is not sufficient to disentangle Arctic greening complexity. The required next steps will be an integration of perspectives and approaches through existing and new international research efforts to address the following critical research gaps: 
1. Addressing scale issues by integrating proximal remote sensing and in-situ observations into circumarctic greening analyses

Analyses of observations across scales will allow us to bridge the gap and improve our mechanistic understanding of the links between in-situ vegetation dynamics and broader remotely-sensed patterns and trends. New instruments for carrying out in-situ and proximal remote-sensing observations for comparison with satellite data are developing rapidly. However, we must urgently develop standardized field data collection protocols. In order to facilitate future synthesis, we need to incorporate data from long-term ecological monitoring ${ }^{12,18,86,94}$, historical imagery ${ }^{116}$, phenocam networks ${ }^{117}$, flux towers ${ }^{118}$, high-resolution imagery such as from aircraft, towers, and drones ${ }^{119}$ and satellites.

2. Incorporation of heterogeneity and uncertainty into analyses to improve confidence in detection of Arctic greening trends

New finer spatial or temporal resolution data will inform analyses of historic greening trends. Current circumarctic Landsat analyses are shedding light on greening trends by exploiting finer spatial resolution data while accounting for the lower temporal resolution of observation records ${ }^{15}$. Recent and ongoing release of finer-resolution satellite datasets (e.g., EU-funded Sentinel missions, Digital Globe, Planet constellations) and data products (e.g., the Arctic Digital Elevation Model) will provide finer spatial (2-10 m) and/or temporal resolution (1-5 days) data across the Arctic ${ }^{120}$. We can gain a better understanding of past spectral greening signals from legacy satellite datasets by conducting standardized reprocessing with for example statistical methods incorporating uncertainty in observations such as image quality information, improved atmospheric corrections and snow detection.

3. Inclusion of new observational tools beyond optical vegetation indices to clarify the mechanistic links between spectral greening and vegetation change

In addition to incorporating finer resolution datasets, new types of data collection can inform our understanding of what greening patterns and trends represent. Emerging remote sensing campaigns using hyperspectral sensors or those that can measure Solar-Induced Fluorescence $(\mathrm{SIF})^{121}$ will 
404

provide new insights into vegetation dynamics. However, future sensor development across satellite, aircraft and near-surface platforms should be designed to maximize comparability. In addition to new data collection, novel data integration approaches, for example those employing machine learning, will provide greater insights into biome-scale analyses linking remote sensing observations with ecological change in high-latitude ecosystems ${ }^{21,122}$.

\section{Conclusions}

Recent research has highlighted the complexity in observed Arctic greening and browning trends. Although satellite data have been used to detect and attribute global change impacts and resulting climate feedbacks in Arctic ecosystems ${ }^{20,22}$, numerous questions and uncertainties remain. The three major challenges in resolving these uncertainties are: 1) improving the clarity of the definitions of widely used terminology associated with greening and browning phenomena, 2) promoting the understanding of the strengths and limitations of vegetation indices when making ecological interpretations and, 3) better incorporating and accounting for different scales of observation and uncertainty in analyses of changing tundra productivity and phenology. New sensors and better access to legacy data are improving our ability to remotely sense vegetation change. However, new data alone will not provide solutions to many of the longstanding conceptual and technical challenges. The complexity of Arctic greening will only be fully understood through multidisciplinary efforts spanning the fields of ecology, remote sensing, earth system science and computer science. As a field, we need to look forwards to quantify contemporary and future change, but also backwards by conducting reanalyses of historical data. Ultimately, we urgently need a deeper understanding of the relationships between patterns and processes in greening and browning dynamics to improve estimates of the globally-significant climate change feedbacks in high-latitude ecosystems ${ }^{20}$. 
427 Table 1. A variety of geophysical ${ }^{13,106,123}$, environmental ${ }^{44,60,61}$ and ecological ${ }^{12,47,49,54,57,110}$ factors can

428 influence the magnitude and direction of change in vegetation indices and are particularly

429 problematic at high latitudes ${ }^{6}$. The effects include: 1) Radiometric effects: differences among satellite

430 datasets including band widths, atmospheric effects, cloud-screening algorithms, sensor

431 degradation, orbital shift and bidirectional reflectance distribution functions originating from

432 differences in field of view and sun geometries. 2) Spectral mixing: the blending of sub-pixel spatial

433 heterogeneity that can influence the overall pixel signal (Figure 2). 3) Adjacency effects: the

434 reflectance of surrounding pixels that can influence the signal of a given pixel (Figure 2). And, 4) a

435 variety of environmental and ecological factors from snow melt and soil moisture dynamics to

436 composition of evergreen versus deciduous or vascular versus non-vascular plants.

Factors Specific effects Influence on apparent greening patterns and trends
influencing
vegetation
indices

Low sun angle Radiometric effects

At high latitudes, low sun angles and cloud shadows can have a greater influence on vegetation indices relative to lower latitudes ${ }^{62}$. NDVI varies with sun angle, an effect magnified in spring and autumn $\mathrm{n}^{62}$. Shadows also reduce NDVI and may be difficult to detect in coarse grained imagery ${ }^{44}$.

Cloud cover Radiometric effects, Spectral mixing, Adjacency effects

Standing water Spectral mixing, Adjacency effects

Snow patches Spectral mixing, adjacency effects

Snow versus phenology dynamics
Thin cloud, fog and smoke can influence imagery, reducing NDVI. Cloud and fog are particularly problematic in coastal regions and can vary greatly between image acquisitions ${ }^{44}$. Cloud-screening algorithms differ among satellite datasets (in part as a function of available spectral bands), and partly cloudy or hazy conditions are particularly difficult for screening algorithms to detect consistently. In addition, the fogginess of Arctic locations can vary over time due to changing temperatures ${ }^{44}$ and/or sea ice conditions ${ }^{124}$.

Standing water ${ }^{60}$ can influence comparisons of vegetation indices across space and may not be detectable in coarse-grained imagery, despite influencing spectral signatures. NDVI values of water are generally low, however shallow water or standing water intermixed with vegetation or algal growth may not be identified as water by quality filters and may have higher NDVI. Water within a pixel may lead to artificially low NDVI values and can influence estimates of NDVI change over time. This is especially relevant to the Arctic during the spring and summer as snow melts and turns into ephemeral ponds and lakes whose spectral signatures will be mixed with nearby vegetation ${ }^{125}$. NDVI signals could be driven by changes in standing water over time associated with changing precipitation, permafrost conditions, and/or warming rather than by changes in vegetation $56,57,60,125,126$.

Sub-pixel sized snow patches will decrease the NDVI for a given tundra area $^{57}$. NDVI values of snow are strongly negative. Earlier snow loss or later snow return may drive a strong positive trend in NDVI. Longer persistence of snow on the landscape in patches may not be filtered by quality algorithms, yet could still lead to lower NDVI values.

Surface reflectance just after snow off is commonly used as the baseline when fitting phenology models. This approach masks the effects of subnivean phenological progression and/or may overemphasise the role of snow-off or snow-on dates as a driver of plant phenology $y^{57,63}$. 


\begin{tabular}{ll}
\hline Soil moisture $\quad$ Spectral mixing & Soil moisture can influence the reflectance of vegetated tundra surfaces \\
& NDVI values are sensitive to soil moisture, which may or may not covary with \\
& vegetation chang $\mathrm{e}^{125}$. Furthermore, NDVI is relatively insensitive to changes \\
& in very sparsely vegetated (e.g., the High Arctic ${ }^{127}$ ) and very densely
\end{tabular}

Plant water content Mosses can absorb water and thus influence surface reflectance of landscapes independent of vascular plant phenology and productivity ${ }^{126}$.

$\begin{array}{ll}\text { Short growing } & \text { Timing of image } \\ \text { season } & \text { acquisition }\end{array}$

Rapid plant phenology
Chosen phenometric

Trends in NDVI metrics and growing season length can be influenced by the timing of data acquisition. To compare spatial patterns in vegetation indices among sites, images are required from the same time within the growing season and the same time points within the day ${ }^{126}$. However, the short growing seasons at high latitudes make image acquisition particularly challenging. Satellites have different temporal frequencies for overpasses thus influencing comparisons. Growing season length decreases at higher latitudes, thus the impact of missing data is of a greater magnitude as latitude increases.

The specific metrics used to quantify phenology will influence the resulting patterns observed ${ }^{91}$. Combining datasets with different spatial and temporal resolutions can limit comparisons (Figure 2). Variation in phenology metrics due to curve-fitting methods can exceed variation in measured phenology signals. Thus, using the same phenological functions across large geographic and ecological gradients, such as across the high latitudes, may introduce biases and/or errors.

Phenological diversity Changes in phenology of individual species or plants growing in particular microclimates can lead to shifts in landscape phenology ${ }^{50}$.

Plant traits and functional groups or types

Isolating changes in plant productivity and canopy structure versus composition

Vascular and deciduous versus non-vascular and evergreen plants
Vegetation indices are related to radiation absorbed by green foliage (APAR), canopy structure, species composition, leaf-level traits and biomass ${ }^{37,39}$ (Figure 2). However, how vegetation indices and ecological properties covary across diverse Arctic ecosystems is not well established. Other factors including bare ground cover, canopy structure, etc. that influence vegetation indices must be accounted for to isolate productivity change from other land surface changes.

Non-vascular or evergreen plants can obscure the deciduous vascular plant seasonal signal ${ }^{49,81}$. Tundra without vascular plants can additionally have a substantial cover of biological soil crust communities consisting of lichens, cyanobacteria, mosses and green algae that may also influence NDVI ${ }^{107,126}$. 
Satellite records indicate greening trends across the circumpolar Arctic
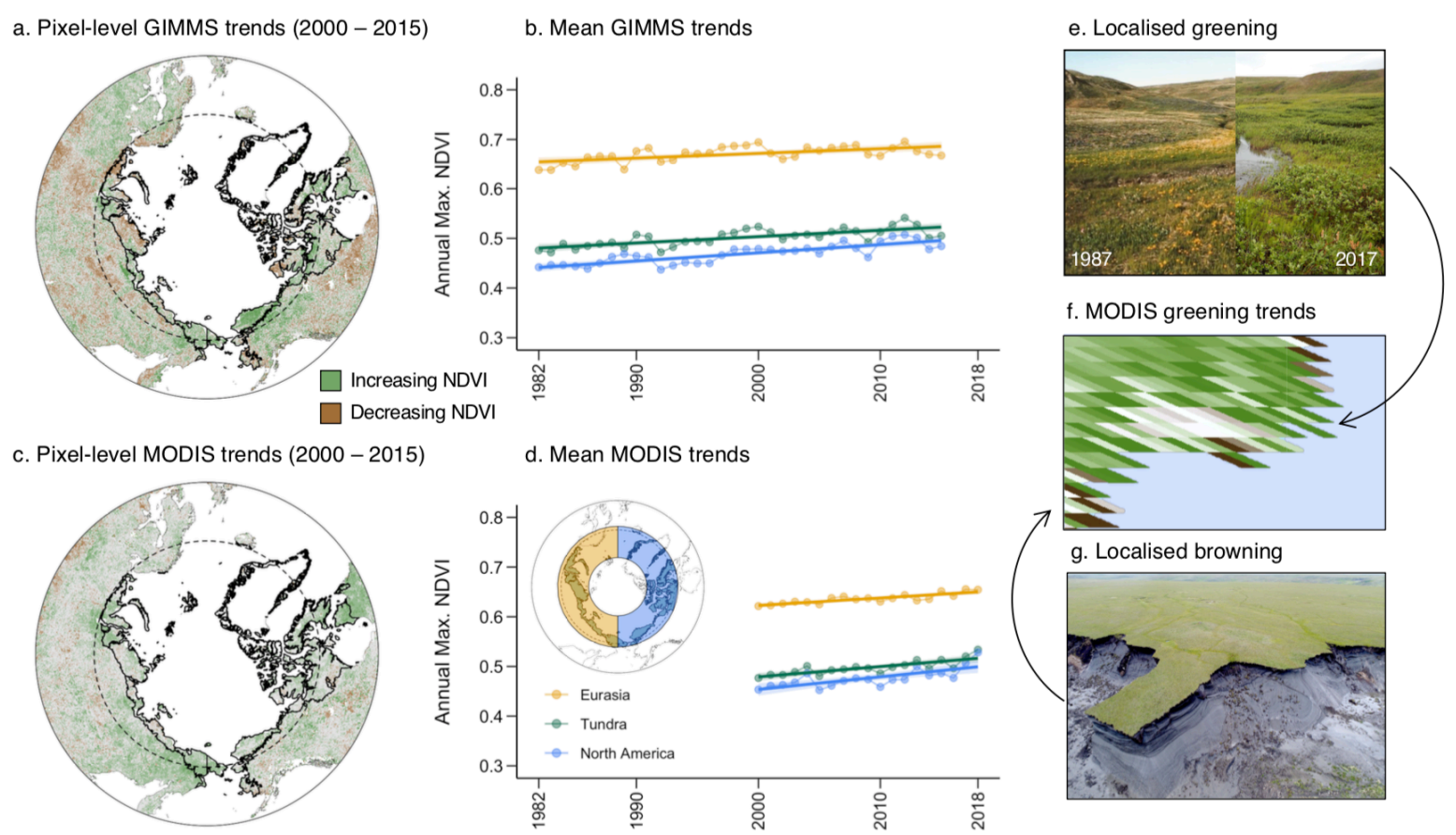

g. Localised browning

Figure 1. Arctic greening, which varies across space and time and among satellite datasets,

interpretation and integration. Trends in maximum NDVI vary spatiotemporally and the magnitude

of changes is different depending on what satellite imagery is analysed ( $a$ and $c$, data subsetted to

temporally overlapping years; $b$ and d, GIMMS3gv1 1982 to 2015 and MODIS MOD13A1v6 2000 to

2018). Regional trends may summarise localised greening, for example shrub encroachment (e) and

browning such as permafrost thaw (g) occurring at the pixel scale on Qikiqtaruk - Herschel Island in

the Canadian Arctic (f). NDVI trends (a and c) were calculated using robust regression (Theil-Sen

estimator) in the Google Earth Engine ${ }^{129}$. Dashed line indicates the Arctic Circle and the black

outlined polygon ( $a$ and $c$ ) and green 'Tundra' line ( $b$ and $d)$ indicates the Arctic tundra region from

449 the Circumpolar Arctic Vegetation Map (www.geobotany.uaf.edu/cavm/). The inset map in $d$ 450 indicates the regions for the mean trends for yellow 'Eurasia' and blue 'North America' polygons. 


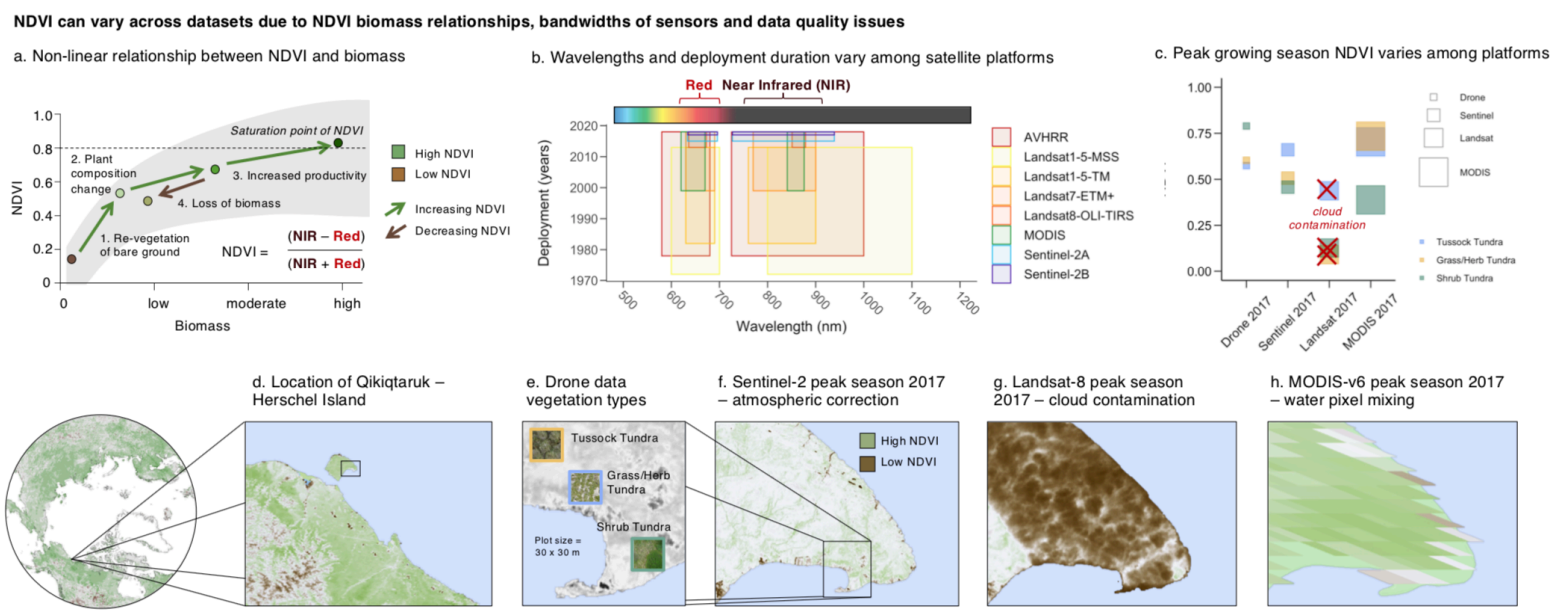

Figure 2. Ecological interpretation of trends in the Normalized Difference Vegetation Index

(NDVI) requires a consideration of non-ecological factors. NDVI, calculated as the difference between red and near infrared bands (NIR), has a non-linear relationship with several common metrics of plant productivity, like biomass and LAI (a). Satellite platforms have different spectral band widths which can influence calculations of NDVI despite shared centre wavelengths (b). NDVI values from commonly available satellite data products and drone datasets (c) differed substantially across products and across plots of three different vegetation types (e) during the period of peak biomass in 2017 on Qikiqtaruk - Herschel Island, Yukon. Here, factors such as a lack of atmospheric correction (f), cloud or fog contamination (g), sub-pixel mixing (h), different plot grain sizes of data in more or less heterogeneous vegetation cover and timing of data acquisition could have all influenced NDVI values. Data were analysed and extracted for $30 \times 30 \mathrm{~m}$ plots from $13^{\text {th }}$ July to $4^{\text {th }}$ August in 2017 using the Google Earth Engine ${ }^{129}$ for the MODIS MYD13A1v6 (pixel size $=500 \mathrm{~m} \times 500 \mathrm{~m}$ ) and Landsat 8 (pixel size $=30 \mathrm{~m} \times 30 \mathrm{~m}$ ) NDVI product, and the top-of-atmosphere Sentinel-2 NDVI product without atmospheric corrections (pixel size $=10 \mathrm{~m} \times 10 \mathrm{~m}$ ) NDVI, and Pix4D-processed drone data collected using a radiometrically calibrated four-band multispectral sensor (Sequoia, pixel size $=12 \mathrm{~cm} \times 12 \mathrm{~cm}$ ) on an FX-61 fixed-wing platform with the High-latitude Drone Ecology Network protocols (https://arcticdrones.org/). We purposefully present data with quality and processing issues above to highlight the challenges in quantifying NDVI in regional-to-global studies where data quality issues may be spatially or temporally variable among locations. 
Spatial heterogeneity in landcover can influence NDVI $\sim$ vegetation relationships

Qikiqtaruk, Canada - low landscape-level heterogeneity and increasing shrub abundance and variable radial growth

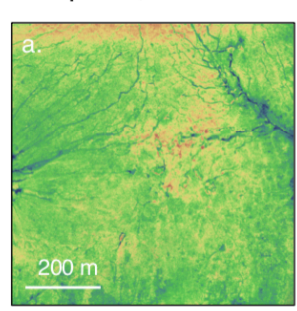

Drone-derived NDVI
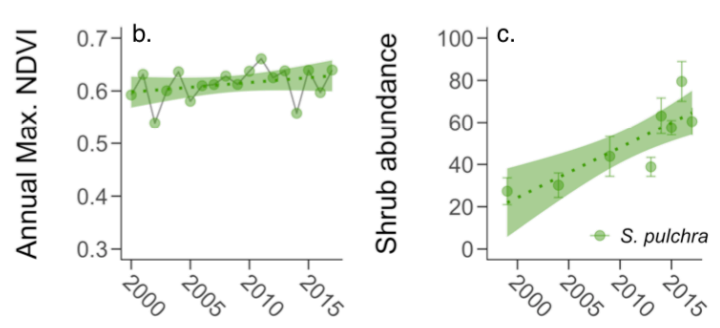

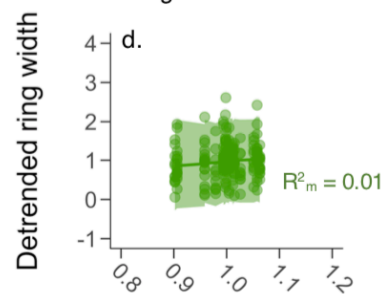

Detrended NDVI

Kangerlussuaq, Greenland - high landscape-level heterogeneity, increased yet stabilized shrub abundance and variable radial growth

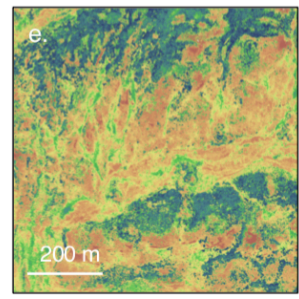

Drone-derived NDVI
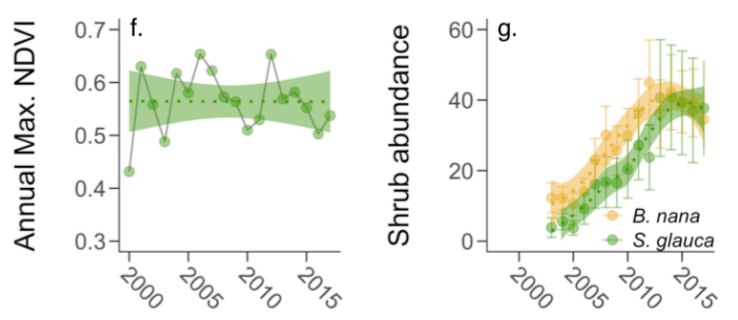

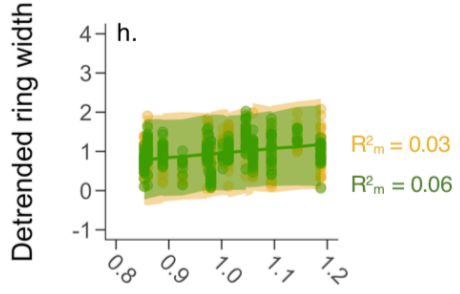

Detrended NDVI

Figure 3. Sub-pixel spatial heterogeneity in vegetative greening and browning cannot be

accurately captured at coarser grains. Landscape patterns $(a, e)$, trends $(b, f)$, and variability (d,

h) in NDVI may not represent in-situ observations of vegetation change. NDVI trends and interannual

variability had mixed correspondence with increases in shrub abundance $(c, g)$ and interannual

variability in shrub growth on Qikiqtaruk - Herschel Island, Yukon ${ }^{94}$ (c, point framing in twelve 1-m ${ }^{2}$

plots; d, Salix pulchra $=21$, https://github.com/ShrubHub/QikiqtarukHub) and Kangerlussuaq,

https://arcticdata.io/catalog/view/doi:10.18739/A24X0Q,

https://arcticdata.io/catalog/view/doi:10.18739/A28Q18,

https://arcticdata.io/catalog/view/doi:10.5065/D6542KRH). Errors are standard error bars around mean values (c, g) and 95\% credible intervals for a Bayesian hierarchical model of the relationship between detrended annual growth rings and NDVI with shrub individual and year as random effects widths explained by detrended NDVI $(d, h)$. Landscape NDVI patterns (a and e) were measured using a Parrot Sequoia and FX-61 fixed wing platform according to High-latitude Drone Ecology Network protocols in the summer of 2017 (https://arcticdrones.org/) and analysed using the Pix4D 
489 software. Coarser-grain NDVI time series (MODIS MOD13A1v6, 500m pixels) were calculated using 490 Google Earth Engine ${ }^{129}$ and the Phenex package in R. 
Plant phenology does not always match land-surface greenness across the growing season
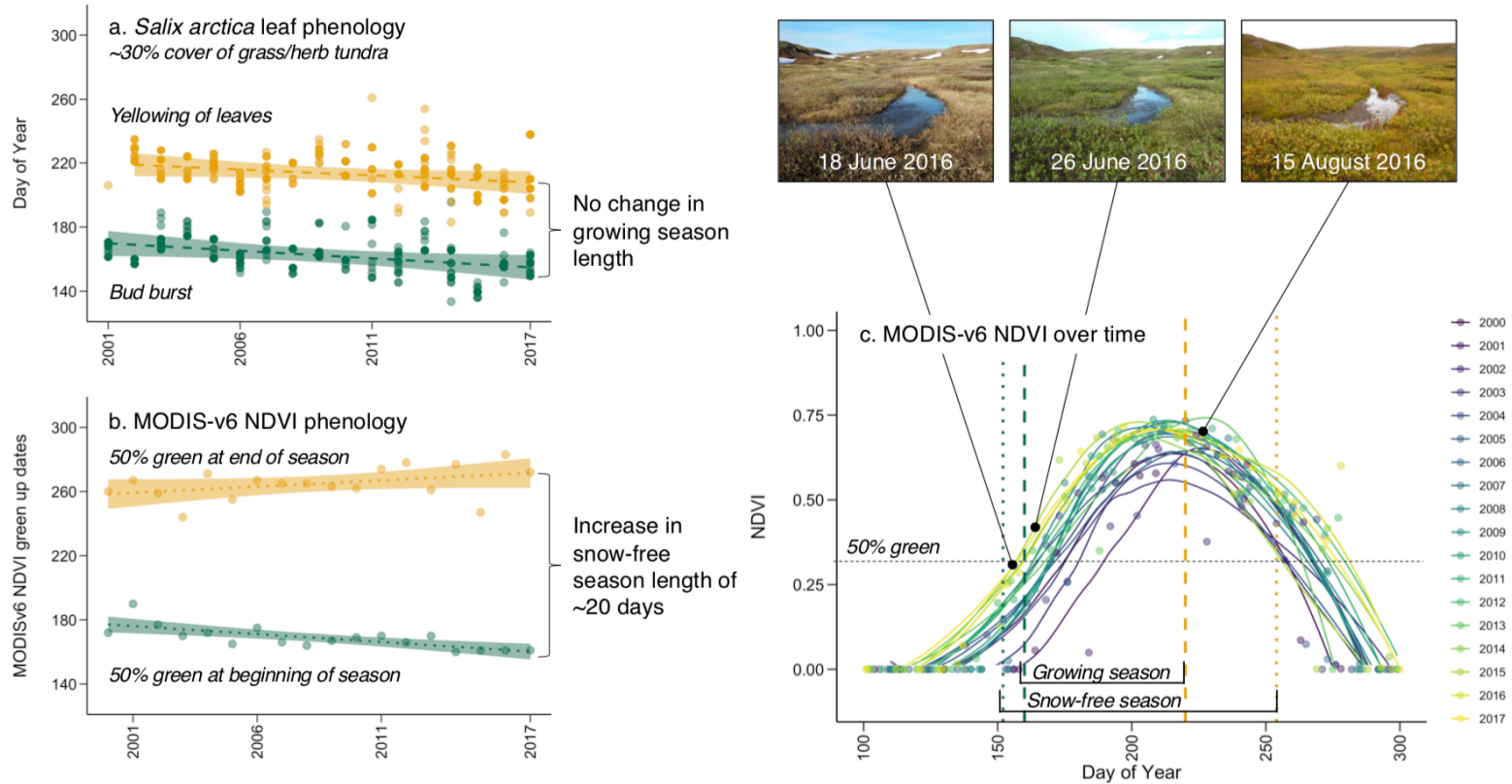

Figure 4. Satellite-derived phenology estimates do not always match with in-situ plant

phenology observations. Satellite-observed snow-free season length of the land surface (here defined as the period with NDVI greater than $50 \%$ of the max NDVI, b and c) might not directly correspond to the growing season of vascular plants in tundra ecosystems, particularly in autumn (a). Snow-melt dynamics can obscure the plant phenology signal and non-vascular or evergreen plants can obscure the deciduous vascular plant seasonal signal. Plant phenology data were collected at 20 monitoring plots on Qikiqtaruk-Herschel Island for the species Salix arctica, which makes up approximately $30 \%$ of the cover in the grass- and forb-dominated vegetation type.

500 Analyses indicate that both leaf emergence and senescence have become earlier, resulting in no 501 change in realized growing season length despite substantial increases in the snow-free period of 502 the land surface ${ }^{94}(a-c$, https://github.com/ShrubHub/QikiqtarukHub). Satellite data are MODIS 503 MOD13A1v6 extracted for the pixel containing the phenology transects using Google Earth Engine ${ }^{129}$ 504 and the Phenex package in $\mathrm{R}(\mathrm{b}$ and $\mathrm{c})$. 
Greening and browning complexity can be addressed by incorporating scale and clarifying ambiguity in terminology

a. Arctic greening patterns and trends are influenced by issues of scale

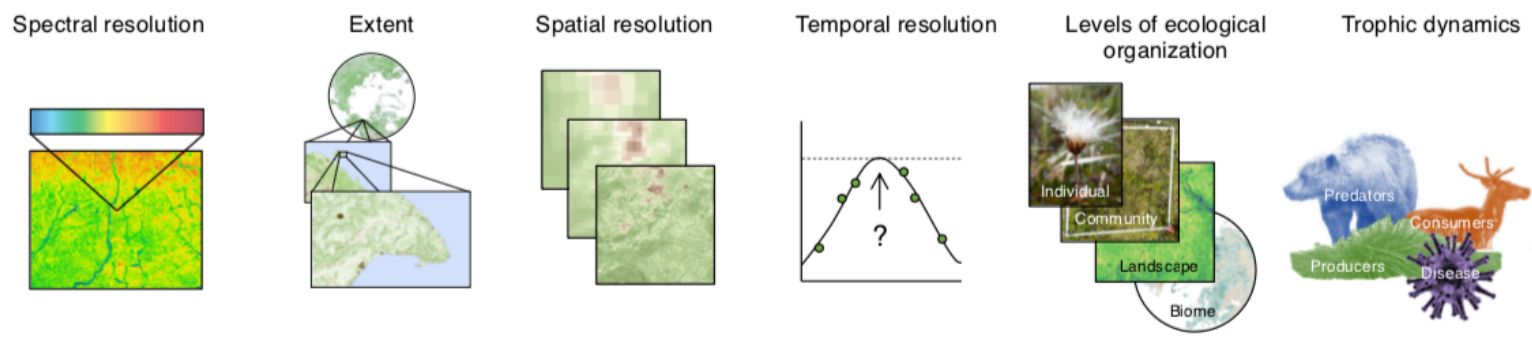

b. Spatial heterogeneity in NDVI greening/browning patterns can influence greening/browning trends over time

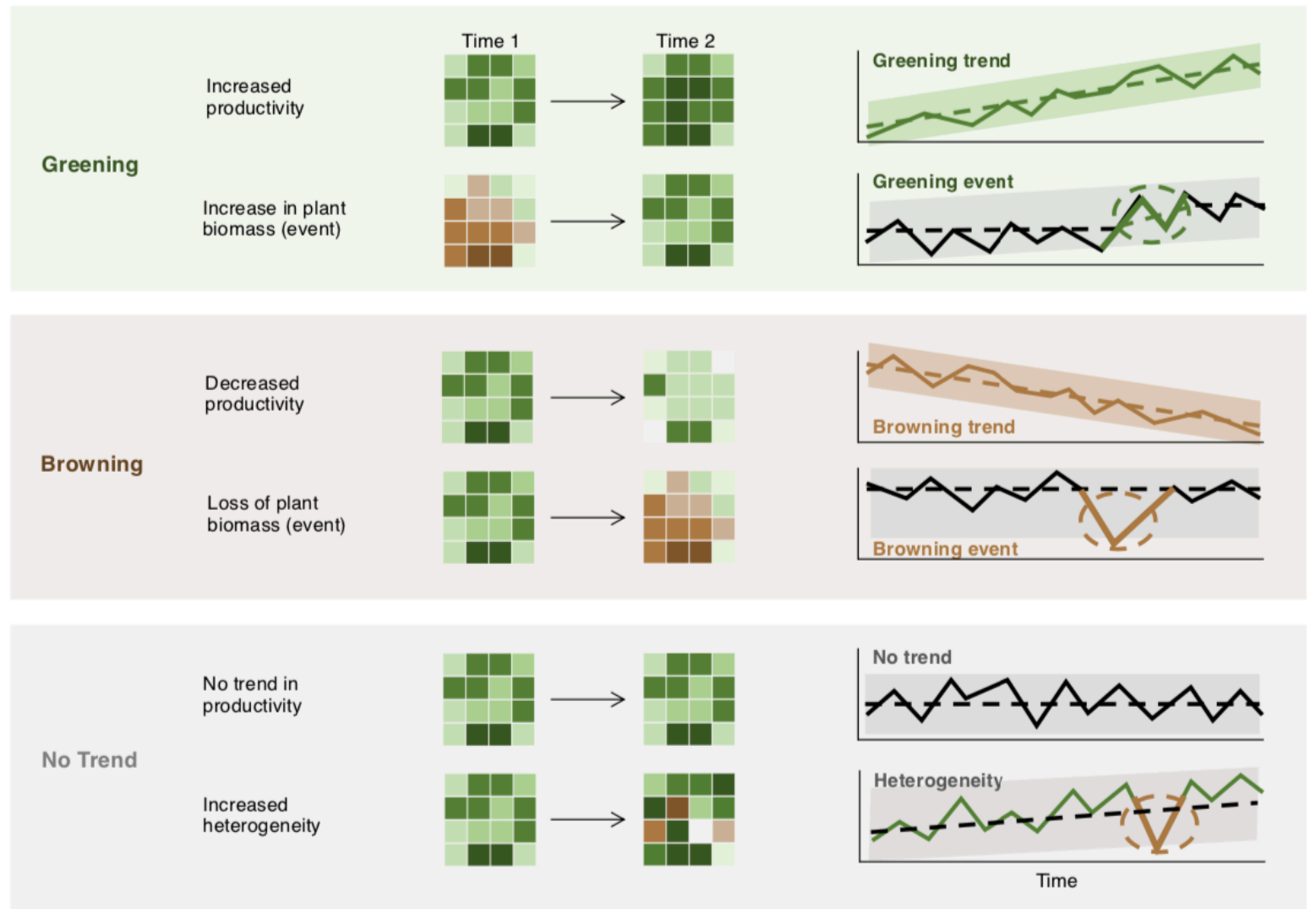

Figure 5. Arctic greening is influenced by both issues of measurement scale and inference across ecological hierarchies. Spectral resolution (Figure 2), extent (Figure 1), spatial resolution

508 (Figure 2), landscape-level heterogeneity (Figure 3), temporal resolution (Figure 4), and ecological factors all influence the interpretation of greening trends (a). Within-pixel changes in land surface greening and browning events and trends can translate into different greening and browning patterns as their effects are scaled up (b). Ecological processes that comprise greening and browning trends include a combination of events, such as a pulse of plant recruitment or growth, a dieback of plants due to an extreme winter climate event, herbivore or disease outbreak or other disturbance and subsequent recovery. Longer-term change such as increasing shrub cover or progression of permafrost disturbances can also influence real-world NDVI time series. These different factors add 
516 complexity to the interpretation of Arctic greening trends. The scale and hierarchy of observations 517 need to be incorporated into and/or accounted for in future analyses of Arctic greening. 
518

\section{Corresponding authors}

Correspondence to Isla Myers-Smith (isla.myers-smith@ed.ac.uk) and Jeffrey Kerby (jeffrey.t.kerby@dartmouth.edu).

\section{Author Contributions}

IHM-S and JTK conducted the analyses and wrote the manuscript with contributions from all authors. GKP, JWB and HE contributed substantially to early versions of the manuscript. IHM-S, JTK, JJA, AMC, CJ, SA-B, HJDT and ESP collected drone and in-situ data. This paper results from two collaborations: the sTundra working group at the German Centre for Integrative Biodiversity Research (iDiv) led by IHM-S, SCE and ADB and the 'Event Drivers of Arctic Browning Workshop' at the University of Sheffield led by GKP.

\section{Funding}

Data collection on Qikiqtaruk-Herschel Island was funded by the UK Natural Environment Research Council (NERC) NE/M016323/1 [to IMS] and a National Geographic Society grant CP-061R-17 and a Parrot Climate Innovation Grant [to JTK]. Data collection at Kangerlussuaq, Greenland was supported by the US National Science Foundation (NSF) grants 0724711, 0713994, 0732168, 0902125, 1107381, 1525636, 1748052 and the National Geographic Society [to EP], as well as an Arctic Institute of North America Grant-in-Aid [to CJ]. The sTundra working group was supported by sDiv, the Synthesis Centre of the German Centre for Integrative Biodiversity Research (iDiv) HalleJena-Leipzig (DFG FZT 118). The Event Drivers of Arctic Browning workshop was funded by P3Plant Production and Protection (http://p3.sheffield.ac.uk/). Several members of the team are supported by the NASA ABoVE program (https://above.nasa.gov/). Additional funding was provided by the Research Council of Norway grant 287402 [to JWB and HT] and 294948 [to FS, JWB, AB, HT, and FJWP], the NERC doctoral training partnership grant NE/L002558/1 [to JJA and HJDT], the US NSF grants PLR-1504134, AGS 15-02150, PLR16-03473 [to LAH], the Natural Sciences and Engineering Research Council of Canada and the Canadian Centennial Scholarship Fund [to SAB], the Academy of Finland decision 256991 and JPI Climate 291581 [to BCF], the NASA ABoVE grants NNX17AE44G and NNX17AE13G [to SJG \& LTB], NSF grants PLR-0632263, PLR-0856516, PLR- 

1432277, PLR-1504224, PLR-1836839 [to RDH], the US NSF grant PLR-1417745 [to MML], an NERC IRF NE/L011859/1 [to MMF], Independent Research Fund Denmark 7027-00133B and Villum Fonden VKR023456 to [SN], the Norwegian Research Council grants 230970 and 274711 and the Swedish Research Council registration 2017-05268 [to FJWP], University of Zurich Research Priority Program on Global Change and Biodiversity [to GS-S] and the US NSF grants OPP-1108425 and PLR-1108425 [to PFS].

\section{Acknowledgements}

We thank John Gammon and Matthias Forkel for their very thoughtful and constructive reviews of the manuscript. We thank the Inuvialuit and Greenlandic People for the opportunity to conduct field research on their land.

\section{Data availability}

Data come from publicly available remote sensing and ecological datasets including:

MODIS (https://modis.gsfc.nasa.gov/), GIMMS3g.v1 (https://nex.nasa.gov/nex/projects/1349/), the High Latitude Drone Ecology Network (https://arcticdrones.org/), shrub abundance, annual growth ring and phenology datasets (https://github.com/ShrubHub/QikiqtarukHub, https://arcticdata.io/catalog/view/doi:10.18739/A24X0Q, https://arcticdata.io/catalog/view/doi:10.18739/A28Q18, https://arcticdata.io/catalog/view/doi:10.5065/D6542KRH).

\section{Code availability}

Code is available in a GitHub repository (https://github.com/ShrubHub/GreeningHub). 
571 1. IPCC. Climate Change 2013: The Physical Science Basis. Contribution of Working Group I to the Fifth Assessment Report of the Intergovernmental Panel on Climate Change. (2013).

2. Post, E. et al. The polar regions in a $2^{\circ} \mathrm{C}$ warmer world. Science Advances 5, eaaw9883 (2019).

Reviews how Arctic warming has outpaced the global average with wide reaching consequences for tundra ecosystems.

3. Bhatt, U. S. et al. Recent declines in warming and vegetation greening trends over Pan-Arctic tundra. Remote Sens. 5, 4229-4254 (2013).

\section{Reports of declines in spectral greening trends across Pan-Arctic tundra ecosystems.}

4. de Jong, R., de Bruin, S., de Wit, A., Schaepman, M. E. \& Dent, D. L. Analysis of monotonic greening and browning trends from global NDVI time-series. Remote Sens. Environ. 115, 692702 (2011).

5. Forbes, B. C., Macias-Fauria, M. \& Zetterberg, P. Russian arctic warming and 'greening' are closely tracked by tundra shrub willows. Glob. Change Biol. 16, 1542-1554 (2010).

Links spectral greening with both warming and tundra shrub growth in the Russian Arctic.

6. Guay, K. C. et al. Vegetation productivity patterns at high northern latitudes: a multi-sensor satellite data assessment. Glob. Change Biol. 20, 3147-3158 (2014).

Reports conflicting patterns in spectral greening trends from different satellite datasets highlighting critical uncertainties in the links between satellite-observed spectral greening trends and in situ vegetation change.

7. Jia, G. J., Epstein, H. E. \& Walker, D. A. Greening of arctic Alaska, 1981-2001. Geophys. Res. Lett. 30, HLS 3-1 (2003).

8. Jia, G. J., Epstein, H. E. \& Walker, D. A. Vegetation greening in the Canadian Arctic related to decadal warming. J. Environ. Monit. 11, 2231 (2009).

9. Ju, J. \& Masek, J. G. The vegetation greenness trend in Canada and US Alaska from 19842012 Landsat data. Remote Sens. Environ. 176, 1-16 (2016). 
10. Macias-Fauria, M., Forbes, B. C., Zetterberg, P. \& Kumpula, T. Eurasian Arctic greening reveals teleconnections and the potential for structurally novel ecosystems. Nature Clim. Change 2, 613-618 (2012).

11. Myneni, R. B., Keeling, C. D., Tucker, C. J., Asrar, G. \& Nemani, R. R. Increased plant growth in the northern high latitudes from 1981 to 1991 . Nature 386, 698-702 (1997).

One of the first studies to report spectral greening trends for Northern high-latitude ecosystems.

12. Phoenix, G. K. \& Bjerke, J. W. Arctic browning: extreme events and trends reversing arctic greening. Glob. Change Biol. 22, 2960-2962 (2016).

Reviews Arctic browning from an ecological perspective capturing the differences between events and trends in spectral greening and browning.

13. Zhang, Y., Song, C., Band, L. E., Sun, G. \& Li, J. Reanalysis of global terrestrial vegetation trends from MODIS products: Browning or greening? Remote Sens. Environ. 191, 145-155 (2017).

14. Zhu, Z. et al. Greening of the Earth and its drivers. Nature Clim. Change 6, 791-795 (2016).

15. National Academies of Sciences, E. Understanding Northern Latitude Vegetation Greening and Browning: Proceedings of a Workshop. (2019). doi:10.17226/25423.

16. Huang, M. et al. Velocity of change in vegetation productivity over northern high latitudes. Nat. Ecol. Evol. 1, 1649 (2017).

17. Metcalfe, D. B. et al. Patchy field sampling biases understanding of climate change impacts across the Arctic. Nat. Ecol. Evol. 2, 1443 (2018).

18. Elmendorf, S. C. et al. Plot-scale evidence of tundra vegetation change and links to recent summer warming. Nature Clim. Change 2, 453-457 (2012).

19. Myers-Smith, I. H. et al. Shrub expansion in tundra ecosystems: dynamics, impacts and research priorities. Environ. Res. Lett. 6, 045509 (2011).

20. IPCC Working Group II. Climate Change 2014: Impacts, Adaptation, and Vulnerability. (2014).

21. Forkel, M. et al. Enhanced seasonal $\mathrm{CO} 2$ exchange caused by amplified plant productivity in northern ecosystems. Science 351, 696-699 (2016). 
22. Pearson, R. G. et al. Shifts in Arctic vegetation and associated feedbacks under climate change. Nature Clim. Change 3, 673-677 (2013).

23. Lara, M. J., Nitze, I., Grosse, G., Martin, P. \& McGuire, A. D. Reduced arctic tundra productivity linked with landform and climate change interactions. Sci. Rep. 8, 2345 (2018).

24. Miles, V. V. \& Esau, I. Spatial heterogeneity of greening and browning between and within bioclimatic zones in northern West Siberia. Environ. Res. Lett. 11, 115002 (2016).

25. Piao, S. et al. Evidence for a weakening relationship between interannual temperature variability and northern vegetation activity. Nat. Commun. 5, 5018 (2014).

26. Bjorkman, A. D. et al. Status and trends in Arctic vegetation: Evidence from experimental warming and long-term monitoring. Ambio (2019) doi:10.1007/s13280-019-01161-6.

27. Martin, A. C., Jeffers, E. S., Petrokofsky, G., Myers-Smith, I. \& Macias-Fauria, M. Shrub growth and expansion in the Arctic tundra: an assessment of controlling factors using an evidencebased approach. Environ. Res. Lett. 12, 085007 (2017).

28. Piao, S., Friedlingstein, P., Ciais, P., Viovy, N. \& Demarty, J. Growing season extension and its impact on terrestrial carbon cycle in the Northern Hemisphere over the past two decades. Global Biogeochem. Cycles 21, GB3018 (2007).

29. Raynolds, M. K., Walker, D. A. \& Maier, H. A. NDVI patterns and phytomass distribution in the circumpolar Arctic. Remote Sens. Environ. 102, 271-281 (2006).

30. Forkel, M. et al. Trend change detection in NDVI time series: Effects of inter-annual variability and methodology. Remote Sens. 5, 2113-2144 (2013).

Highlights how the analyzed satellite dataset, the corresponding spatiotemporal resolution, and the applied statistical method influence the detection of spectral greening trends.

31. Tucker, C. J. et al. An extended AVHRR 8-km NDVI dataset compatible with MODIS and SPOT vegetation NDVI data. Int. J. Remote Sens. 26, 4485-4498 (2005).

32. Pinzon, J. E. \& Tucker, C. J. A non-stationary 1981-2012 AVHRR NDVI3g time series. Remote Sens. 6, 6929-6960 (2014).

33. Huete, A. et al. Overview of the radiometric and biophysical performance of the MODIS vegetation indices. Remote Sens. Environ. 83, 195-213 (2002). 
653

654

655

656

657

658

659

660

661

662

663

664

665

666

667

668

669

670

671

672

673

674

675

676

677

678

679

34. Brown, T. B. et al. Using phenocams to monitor our changing Earth: toward a global phenocam network. Front. Ecol. Environ. 14, 84-93 (2016).

35. Myneni, R. B., Hall, F. G., Sellers, P. J. \& Marshak, A. L. The interpretation of spectral vegetation indexes. IEEE Trans. Geosci. Remote Sens. 33, 481-486 (1995).

36. Forkel, M. et al. Codominant water control on global interannual variability and trends in land surface phenology and greenness. Glob. Change Biol. 21, 3414-3435 (2015).

37. Myneni, R. B. \& Williams, D. L. On the relationship between FAPAR and NDVI. Remote Sens. Environ. 49, 200-211 (1994).

38. Zhu, Z. et al. Global data sets of vegetation leaf area index (LAl)3g and fraction of photosynthetically active radiation (FPAR) $3 g$ derived from global inventory modeling and mapping studies (GIMMS) normalized difference vegetation index (NDVI3g) for the period 1981 to 2011. Remote Sens. 5, 927-948 (2013).

39. Sellers, P. J. Canopy reflectance, photosynthesis, and transpiration, II. The role of biophysics in the linearity of their interdependence. Remote Sens. Environ. 21, 143-183 (1987).

40. Benedetti, R. \& Rossini, P. On the use of NDVI profiles as a tool for agricultural statistics: The case study of wheat yield estimate and forecast in Emilia Romagna. Remote Sens. Environ. 45, 311-326 (1993).

41. Goetz, S. J. \& Prince, S. D. Modelling terrestrial carbon exchange and storage: Evidence and implications of functional convergence in light-use efficiency. in Advances in Ecological Research (eds. Fitter, A. H. \& Raffaelli, D.) vol. 28 57-92 (Academic Press, 1999).

42. Wang, L. \& Fensholt, R. Temporal changes in coupled vegetation phenology and productivity are biome-specific in the Northern Hemisphere. Remote Sens. 9, 1277 (2017).

43. Bhatt, U. S. et al. Changing seasonality of panarctic tundra vegetation in relationship to climatic variables. Environ. Res. Lett. 12, 055003 (2017).

44. Karlsen, S. R., Anderson, H. B., Wal, R. van der \& Hansen, B. B. A new NDVI measure that overcomes data sparsity in cloud-covered regions predicts annual variation in ground-based estimates of high arctic plant productivity. Environ. Res. Lett. 13, 025011 (2018). 
45. Fensholt, R. \& Proud, S. R. Evaluation of Earth Observation based global long term vegetation trends - Comparing GIMMS and MODIS global NDVI time series. Remote Sens. Environ. 119, 131-147 (2012).

46. Tian, F. et al. Evaluating temporal consistency of long-term global NDVI datasets for trend analysis. Remote Sens. Environ. 163, 326-340 (2015).

47. Pattison, R. R., Jorgenson, J. C., Raynolds, M. K. \& Welker, J. M. Trends in NDVI and tundra community composition in the Arctic of NE Alaska between 1984 and 2009. Ecosystems 18, 707-719 (2015).

48. Bjorkman, A. D. et al. Plant functional trait change across a warming tundra biome. Nature 562, 57-62 (2018).

49. Boelman, N. T., Gough, L., McLaren, J. R. \& Greaves, H. Does NDVI reflect variation in the structural attributes associated with increasing shrub dominance in arctic tundra? Environ. Res. Lett. 6, 035501 (2011).

50. Prevéy, J. S. et al. Warming shortens flowering seasons of tundra plant communities. Nat. Ecol. Evol. 3, 45 (2019).

51. Oberbauer, S. F. et al. Phenological response of tundra plants to background climate variation tested using the International Tundra Experiment. Phil. Trans. R. Soc. B 368, (2013).

52. Post, E., Steinman, B. A. \& Mann, M. E. Acceleration of phenological advance and warming with latitude over the past century. Sci. Rep. 8, 3927 (2018).

53. Berner, L. T., Jantz, P., Tape, K. D. \& Goetz, S. J. Tundra plant above-ground biomass and shrub dominance mapped across the North Slope of Alaska. Environ. Res. Lett. 13, 035002 (2018).

54. Blok, D. et al. The response of Arctic vegetation to the summer climate: relation between shrub cover, NDVI, surface albedo and temperature. Environ. Res. Lett. 6, 035502 (2011).

55. Grosse, G., Goetz, S., McGuire, A. D., Romanovsky, V. E. \& Schuur, E. A. G. Changing permafrost in a warming world and feedbacks to the Earth system. Environ. Res. Lett. 11, 040201 (2016).

56. Brown, R., Derksen, C. \& Wang, L. Assessment of spring snow cover duration variability over northern Canada from satellite datasets. Remote Sens. Environ. 111, 367-381 (2007). 
57. Gamon, J. A., Huemmrich, K. F., Stone, R. S. \& Tweedie, C. E. Spatial and temporal variation in primary productivity (NDVI) of coastal Alaskan tundra: Decreased vegetation growth following earlier snowmelt. Remote Sens. Environ. 129, 144-153 (2013).

Highlights how spectral greening trends can be associated with soil moisture and growing degree days rather than earlier snowmelt emphasizing the complexity in Arctic greening and environmental change.

58. Goswami Santonu, Gamon John A. \& Tweedie Craig E. Surface hydrology of an arctic ecosystem: Multiscale analysis of a flooding and draining experiment using spectral reflectance. J. Geophys. Res. Biogeosciences 116, (2011).

59. Liu, N., Budkewitsch, P. \& Treitz, P. Examining spectral reflectance features related to Arctic percent vegetation cover: Implications for hyperspectral remote sensing of Arctic tundra. Remote Sens. Environ. 192, 58-72 (2017).

60. Raynolds, M. K. \& Walker, D. A. Increased wetness confounds Landsat-derived NDVI trends in the central Alaska North Slope region, 1985-2011. Environ. Res. Lett. 11, 085004 (2016).

61. Riihimäki, H., Heiskanen, J. \& Luoto, M. The effect of topography on arctic-alpine aboveground biomass and NDVI patterns. Int. J. Appl. Earth Obs. 56, 44-53 (2017).

62. Stow, D. A. et al. Remote sensing of vegetation and land-cover change in Arctic Tundra Ecosystems. Remote Sens. Environ. 89, 281-308 (2004).

Highlights the issues with satellite records of spectral greening due to cloud contamination, low sun angle, surface water and other factors.

63. Wang, S. et al. Limitations and challenges of MODIS-derived phenological metrics across different landscapes in pan-Arctic regions. Remote Sens. 10, 1784 (2018).

64. Bjerke, J. W. et al. Record-low primary productivity and high plant damage in the Nordic Arctic Region in 2012 caused by multiple weather events and pest outbreaks. Environ. Res. Lett. 9, 084006 (2014).

65. Bokhorst, S. et al. Impacts of extreme winter warming in the sub-arctic: growing season responses of dwarf shrub heathland. Glob. Change Biol. 14, 2603-2612 (2008).

66. Richardson, A. D. et al. Ecosystem warming extends vegetation activity but heightens vulnerability to cold temperatures. Nature 560, 368 (2018). 
738

67. Bjerke, J. W. et al. Understanding the drivers of extensive plant damage in boreal and Arctic ecosystems: Insights from field surveys in the aftermath of damage. Sci. Total Environ. 599600, 1965-1976 (2017).

68. Jepsen, J. U. et al. Ecosystem impacts of a range expanding forest defoliator at the foresttundra ecotone. Ecosystems 16, 561-575 (2013).

69. Lund, M. et al. Larval outbreaks in West Greenland: Instant and subsequent effects on tundra ecosystem productivity and CO2 exchange. Ambio 46, 26-38 (2017).

70. Post, E. S., Pedersen, C., Wilmers, C. C. \& Forchhammer, M. C. Phenological sequences reveal aggregate life history response to climatic warming. Ecology 89, 363-370 (2008).

71. Johnson, D. R. et al. Exclusion of brown lemmings reduces vascular plant cover and biomass in Arctic coastal tundra: resampling of a 50 + year herbivore exclosure experiment near Barrow, Alaska. Environ. Res. Lett. 6, 045507 (2011).

72. Fritz, M., Vonk, J. E. \& Lantuit, H. Collapsing Arctic coastlines. Nature Clim. Change (2017) doi:10.1038/nclimate3188.

73. Lantz, T. C., Kokelj, S. V. \& Fraser, R. H. Ecological recovery in an Arctic delta following widespread saline incursion. Ecol. Appl. 25, 172-185 (2015).

74. Nitze, I. et al. Landsat-based trend analysis of lake dynamics across northern permafrost regions. Remote Sens. 9, 640 (2017).

75. Smith, L. C., Sheng, Y., MacDonald, G. M. \& Hinzman, L. D. Disappearing Arctic Lakes. Science 308, 1429-1429 (2005).

76. Rocha, A. V. et al. The footprint of Alaskan tundra fires during the past half-century: implications for surface properties and radiative forcing. Environ. Res. Lett. 7, 044039 (2012).

77. Mack, M. C. et al. Carbon loss from an unprecedented arctic tundra wildfire. Nature 475, 489492 (2011).

78. Park, T. et al. Changes in growing season duration and productivity of northern vegetation inferred from long-term remote sensing data. Environ. Res. Lett. 11, 084001 (2016).

Reports that spectral greening trends are more prevalent than spectral browning trends and that there are strong regional differences in satellite-derived estimates of growing season duration and productivity. 
79. Fraser, R., Olthof, I., Carrière, M., Deschamps, A. \& Pouliot, D. A method for trend-based change analysis in Arctic tundra using the 25-year Landsat archive. Polar Rec. 48, 83-93 (2012).

80. Frost, G. V., Epstein, H. E. \& Walker, D. A. Regional and landscape-scale variability of Landsat-observed vegetation dynamics in northwest Siberian tundra. Environ. Res. Lett. 9, 025004 (2014).

81. Raynolds, M. K., Walker, D. A., Verbyla, D. \& Munger, C. A. Patterns of Change within a Tundra Landscape: 22-year Landsat NDVI Trends in an Area of the Northern Foothills of the Brooks Range, Alaska. Arctic, Antarctic, and Alpine Research 45, 249-260 (2013).

82. Weijers, S., Pape, R., Löffler, J. \& Myers-Smith, I. H. Contrasting shrub species respond to early summer temperatures leading to correspondence of shrub growth patterns. Environ. Res. Lett. 13, 034005 (2018).

83. Brehaut, L. \& Danby, R. K. Inconsistent relationships between annual tree ring-widths and satellite-measured NDVI in a mountainous subarctic environment. Ecol. Indic. 91, 698-711 (2018).

84. Gamm, C. M. et al. Declining growth of deciduous shrubs in the warming climate of continental western Greenland. J. Ecol. 106, 640-654 (2018).

85. Ropars, P. et al. Different parts, different stories: climate sensitivity of growth is stronger in root collars vs. stems in tundra shrubs. Glob. Change Biol. 23, 3281-3291 (2017).

86. Elmendorf, S. C. et al. Experiment, monitoring, and gradient methods used to infer climate change effects on plant communities yield consistent patterns. PNAS 112, 448-452 (2015).

87. Myers-Smith, I. H. et al. Climate sensitivity of shrub growth across the tundra biome. Nature Clim. Change 5, 887-891 (2015).

88. Zeng, H., Jia, G. \& Epstein, H. Recent changes in phenology over the northern high latitudes detected from multi-satellite data. Environ. Res. Lett. 6, 045508 (2011).

89. Zeng, H., Jia, G. \& Forbes, B. C. Shifts in Arctic phenology in response to climate and anthropogenic factors as detected from multiple satellite time series. Environ. Res. Lett. 8, 035036 (2013). 
90. Park, T. et al. Changes in timing of seasonal peak photosynthetic activity in northern ecosystems. Glob. Change Biol. 25, 2382-2395 (2019).

91. Helman, D. Land surface phenology: What do we really 'see' from space? Sci. Total Environ. 618, 665-673 (2018).

92. Callaghan, T. V. et al. Multiple effects of changes in Arctic snow cover. Ambio 40, 32-45 (2011).

93. Liu, Q. et al. Extension of the growing season increases vegetation exposure to frost. Nat. Commun. 9, 426 (2018).

94. Myers-Smith, I. H. et al. Eighteen years of ecological monitoring reveals multiple lines of evidence for tundra vegetation change. Ecol. Monogr. 89, e01351 (2019).

95. Westergaard-Nielsen, A. et al. Transitions in high-Arctic vegetation growth patterns and ecosystem productivity tracked with automated cameras from 2000 to 2013 . Ambio 46, 39-52 (2017).

96. Oehri, J., Schmid, B., Schaepman-Strub, G. \& Niklaus, P. A. Biodiversity promotes primary productivity and growing season lengthening at the landscape scale. PNAS 114, 10160-10165 (2017).

97. Armstrong, J. B., Takimoto, G., Schindler, D. E., Hayes, M. M. \& Kauffman, M. J. Resource waves: phenological diversity enhances foraging opportunities for mobile consumers. Ecology 97, 1099-1112 (2016).

98. Khorsand Rosa, R. et al. Plant phenological responses to a long-term experimental extension of growing season and soil warming in the tussock tundra of Alaska. Glob. Change Biol. 21, 4520-4532 (2015).

99. Sweet, S. K., Gough, L., Griffin, K. L. \& Boelman, N. T. Tall deciduous shrubs offset delayed start of growing season through rapid leaf development in the Alaskan Arctic tundra. Arct. Antarct. Alp. Res. 46, 682-697 (2014).

100. Sweet, S. K., Griffin, K. L., Steltzer, H., Gough, L. \& Boelman, N. T. Greater deciduous shrub abundance extends tundra peak season and increases modeled net CO2 uptake. Glob. Change Biol. 21, 2394-2409 (2015). 
823

101. Verbesselt, J., Hyndman, R., Newnham, G. \& Culvenor, D. Detecting trend and seasonal changes in satellite image time series. Remote Sens. Environ. 114, 106-115 (2010).

102. Tucker, C. J. et al. Higher northern latitude normalized difference vegetation index and growing season trends from 1982 to 1999. Int. J. Biometeorol. 45, 184-190 (2001).

103. Høye, T. T., Post, E., Meltofte, H., Schmidt, N. M. \& Forchhammer, M. C. Rapid advancement of spring in the High Arctic. Curr. Biol 17, R449-R451 (2007).

104. Harsch, M. A., Hulme, P. E., McGlone, M. S. \& Duncan, R. P. Are treelines advancing? A global meta-analysis of treeline response to climate warming. Ecol. Lett. 12, 1040-1049 (2009).

105. Myers-Smith, I. H. \& Hik, D. S. Climate warming as a driver of tundra shrubline advance. J. Ecol. 106, 547-560 (2017).

106. Wang, D. et al. Impact of sensor degradation on the MODIS NDVI time series. Remote Sens. Environ. 119, 55-61 (2012).

107. Williams, L. et al. Biological soil crusts of Arctic Svalbard and of Livingston Island, Antarctica. Polar Biol. 40, 399-411 (2017).

108. Gallo, K., Ji, L., Reed, B., Dwyer, J. \& Eidenshink, J. Comparison of MODIS and AVHRR 16day normalized difference vegetation index composite data. Geophys. Res. Lett. 31, (2004).

109. Shi, C. \& Wang, L. Incorporating spatial information in spectral unmixing: A review. Remote Sens. Environ. 149, 70-87 (2014).

110. Raynolds, M. K., Walker, D. A., Epstein, H. E., Pinzon, J. E. \& Tucker, C. J. A new estimate of tundra-biome phytomass from trans-Arctic field data and AVHRR NDVI. Remote Sens. Lett. 3, 403-411 (2012).

111. Anderson, C. B. Biodiversity monitoring, earth observations and the ecology of scale. Ecol. Lett. 21, 1572-1585 (2018).

112. Estes, L. et al. The spatial and temporal domains of modern ecology. Nat. Ecol. Evol. 2, 819 (2018).

113. Woodcock, C. E. \& Strahler, A. H. The factor of scale in remote sensing. Remote Sens. Environ. 21, 311-332 (1987). 
851

114. Buitenwerf, R., Rose, L. \& Higgins, S. I. Three decades of multi-dimensional change in global leaf phenology. Nature Clim. Change 5, 364-368 (2015).

115. White, M. A. et al. Intercomparison, interpretation, and assessment of spring phenology in North America estimated from remote sensing for 1982-2006. Glob. Change Biol. 15, 23352359 (2009).

116. Tape, K. D., Sturm, M. \& Racine, C. H. The evidence for shrub expansion in Northern Alaska and the Pan-Arctic. Glob. Change Biol. 12, 686-702 (2006).

117. Richardson, A. D. et al. Tracking vegetation phenology across diverse North American biomes using PhenoCam imagery. Sci. Data 5, 180028 (2018).

118. Euskirchen, E. S., Bret-Harte, M. S., Shaver, G. R., Edgar, C. W. \& Romanovsky, V. E. LongTerm Release of Carbon Dioxide from Arctic Tundra Ecosystems in Alaska. Ecosystems 20, 960-974 (2017).

119. Duffy, J. P. et al. Location, location, location: considerations when using lightweight drones in challenging environments. Remote Sens. Ecol. Cons. 0, (2017).

120. Dash, J. \& Ogutu, B. O. Recent advances in space-borne optical remote sensing systems for monitoring global terrestrial ecosystems. Prog. Phys. Geog. 40, 322-351 (2016).

121. Luus, K. A. et al. Tundra photosynthesis captured by satellite-observed solar-induced chlorophyll fluorescence. Geophys. Res. Lett. 44, 1564-1573 (2017).

122. Forkel, M. et al. Identifying environmental controls on vegetation greenness phenology through model-data integration. Biogeosciences 11, 7025-7050 (2014).

123. Tian, F. et al. Evaluating temporal consistency of long-term global NDVI datasets for trend analysis. Remote Sens. Environ. 163, 326-340 (2015).

124. Wilson, A. M. \& Jetz, W. Remotely sensed high-resolution global cloud dynamics for predicting ecosystem and biodiversity distributions. PLOS Biology 14, e1002415 (2016).

125. Arndt, K. et al. Arctic greening associated with lengthening growing seasons in Northern Alaska. Environ. Res. Lett. (2019) doi:10.1088/1748-9326/ab5e26.

126. May, J. L., Parker, T., Unger, S. \& Oberbauer, S. F. Short term changes in moisture content drive strong changes in Normalized Difference Vegetation Index and gross primary productivity in four Arctic moss communities. Remote Sens. Environ. 212, 114-120 (2018). 
880 127. Vickers, H. et al. Changes in greening in the high Arctic: insights from a 30 year AVHRR max 881 NDVI dataset for Svalbard. Environ. Res. Lett. 11, 105004 (2016).

882 128. Loranty, M. M. et al. Vegetation indices do not capture forest cover variation in upland Siberian 883 larch forests. Remote Sens. 10, 1686 (2018).

884 129. Gorelick, N. et al. Google Earth Engine: Planetary-scale geospatial analysis for everyone. $885 \quad$ Remote Sensing of Environment 202, 18-27 (2017).

886 130. Post, E. Erosion of community diversity and stability by herbivore removal under warming. 887 Proc. R. Soc. B 280, 20122722 (2013). 